\title{
Interferência da corticoterapia antenatal nos níveis de glicose e lactato de cabritos prematuros
}

Francisco Leydson Formiga Feitosa", Juliane Teramachi Trevizan, Eva Liliane dos Santos Silva, Jefferson Filgueira Alcindo, Carlos Henrique Berlatto Cancelli, Marcela da Coll de Camargo, Maria Carolina Eugênia Facion, Fernanda Bovino, Luis Cláudio Nogueira Mendes, Luis Gustavo Narciso

Faculdade de Medicina Veterinária, Universidade Estadual Paulista (UNESP), Araçatuba, PR, Brasil

*Autor correspondente

e-mail: leydsonf@fmva.unesp.br

\section{Resumo}

Com o avanço da caprinocultura, diversos estudos estão surgindo para conter grandes perdas, principalmente no período perinatal, sendo estas causadas geralmente por agentes infecciosos, estresse severo, deficiências nutricionais, erro de manejo com os recém-nascidos, entre outros. Durante a vida neonatal, a glicose é responsável por manter a homeostase, já que nesse período torna-se necessário o equilíbrio entre a ingestão e a produção endógena. 0 lactato desempenha papel central como marcador de sofrimento fetal e neonatal. Foram utilizados 28 cabritos prematuros com, aproximadamente, 141 dias de vida, oriundos de cabras submetidas a diferentes protocolos de corticoterapia (por via intramuscular), a saber: grupo I constituído por sete cabritos, com dosagem única de $20 \mathrm{mg}$ de dexametasona, dois dias antes da cirurgia eletiva (139 dias); grupo II - composto por sete cabritos com dosagens de 2 mg de dexametasona, dos 133 aos 136 dias, 4 mg dos 137 aos 138 dias e 20 mg aos 139 dias de prenhez; grupo III - constituído por sete cabritos, com dosagem de 16 mg de dexametasona aos 139 dias, com doses repetidas a cada 12 horas até a cirurgia eletiva. A mensuração da glicemia e do lactato plasmático foram realizadas imediatamente após o nascimento (M0) e a 1 (M1), 12 (M12), 24 (M24) e 48 (M48) horas de vida. Utilizaram-se o glicosímetro One Touch Ultra IIR (Johnson \& Johnson) e o lactímetro Accutrend PlusR (Roche), ambos seguindo as recomendações dos fabricantes. Para a análise estatística, utilizou-se o teste de normalidade Shapiro-Wilk, e para verificar diferenças entre os grupos, ANOVA com pós-teste de Holm-Sidak ou Kruskal-Wallis com pós-teste de Dunn. Os resultados obtidos nos protocolos I, II e III foram os seguintes : glicose M0 (41,57 \pm $19,62 ; 53,14 \pm 35,88 ; 47,14 \pm 13,19)$, M1 (95 $\pm 70,57 ; 55,14 \pm 35,37 ; 46,42 \pm 22,85)$, M12 (62,66 \pm 57,09; $85,71 \pm 60,36 ; 69,85 \pm 34,56)$, M24 (84,33 \pm 72,53; 87,71 \pm 48,59; 104,57 \pm 53,54) e M48 (78,66 \pm 70,73; $89,14 \pm 36,54 ; 99,14 \pm 70,83)$. Já os valores de lactato para os protocolos I, II e III foram: M0 (10,64 $\pm 2,39$; 9,17 $\pm 3,26 ; 11,32 \pm 2,63)$, M1 (12,24 \pm 4,96; 8,78 $\pm 3,91 ; 10,7 \pm 3,78)$, M12 (5,68 $\pm 4,96 ; 7,71 \pm 1,48 ; 6,08 \pm$ 2,82), M24 (4,66 $\pm 3,9 ; 6,88 \pm 2,29 ; 6,51 \pm 3,07)$, M48 (4,78 $\pm 4,06 ; 6,17 \pm 1,56 ; 5,35 \pm 3,77)$. Ao comparar 
os diferentes protocolos de dexametasona, não foram observadas diferenças estatisticamente significativas. Portanto, conclui-se que os níveis de lactato e de glicose de cabritos prematuros após o nascimento não são influenciados pelas diferentes doses de corticoterapia em cabras nos dias que antecedem a parição. 